\title{
Accuracy of genomic values predicted using deregressed predicted breeding values as response variables
}

\section{Exactitud de valores genómicos predichos utilizando como variable de respuesta valores genéticos predichos ajustados}

\author{
Fernanda Ramírez-Floresa, Rufino López-Ordaza , J oel Domínguez-Viveros ${ }^{b}$, \\ José Guadalupe García-Muñiza , Agustín Ruíz-Flores ${ }^{a^{*}}$
}

\begin{abstract}
Highly accurate predicted genetic values must be obtained at an early age to promote rapid genetic progress. The objectives of this study were to compare accuracies $\left(R^{2}\right)$ of genomic values (GVs) and to estimate genetic correlation between true genetic values and genomic values obtained using predicted breeding values (EBV) and deregressed EBV (DEBV) as response variables. A first population, effective population size 800 and 100 generations, was simulated using the QMSim program to generate linkage disequilibrium. Thereafter, 20 males and 200 females were used to generate a second 14-generation population, with 6,400 individuals per generation and its corresponding phenotype and genotype in SNP terms. Generations 7 to 14 of the second population were used in several combinations as training (PEn) and evaluation (PEv) subpopulations. GVs, their accuracies, and genetic correlations were obtained using the GenSel and ASREML programs. When PEn was the largest, the mean $\mathbf{R}^{2}$ of GV was the highest, $0.77 \pm 0.01$. The closer PEn was to PEv, the higher the $R^{2}$, and correspondingly, the lower the predicted error variance. The trends for $\mathbf{R}^{2}$ and PEV held true for both EBV and DEBV used as response variables. Genetic correlation estimates between true genetic values and GVs varied from 0.41 to 0.53 in the two scenarios studied. They decreased when PEn and PEv were farther apart. There were only slight advantages of using DEBVs as response variables over using EBVs.
\end{abstract}

KEY WORDS: Genomic evaluation, Deregressed predicted genetic value, Genomic predicted value, Accuracy, Genetic correlation.

\section{RESUMEN}

Los valores genéticos de individuos en una población deben obtenerse de forma precisa y a edad temprana para promover un progreso genético rápido. Los objetivos de este estudio fueron comparar las exactitudes ( $\mathbf{R}^{2}$ ) de valores genómicos predichos (GBV) y estimar la correlación genética entre los valores genéticos verdaderos (TGV) y los GBV, utilizando los valores genéticos estimados (EBV) y EBV ajustados (DEBV) como variables respuesta. Una primera población de 100 generaciones con tamaño efectivo 800 se simuló con el programa QMSim para generar desequilibrio de ligamiento. Posteriormente, se utilizaron 20 machos y 200 hembras por generación en una segunda población de 14 generaciones, con 6,400 individuos por generación y sus correspondientes fenotipos y genotipos en términos de SNP. Las generaciones 7 a 14 de la segunda población se usaron como subpoblaciones de entrenamiento (PT) y evaluación (PE). Los GBV, sus exactitudes y correlaciones genéticas se obtuvieron utilizando los programas GenSel y ASREML. Cuando la PT fue la más grande, $R^{2}$ media fue la más alta, $0.77 \pm 0.01$. Cuanto más cercana es PT a PE, mayor $R^{2}$, y menor la varianza del error de predicción (PEV). Las tendencias para $R^{2}$ y PEV se mantuvieron tanto para EBV como para DEBV utilizadas como variables de respuesta. Los estimadores de correlación genética entre TGV y GBV variaron de 0.41 a 0.53 en los dos escenarios estudiados. La $\mathbf{R}^{2}$ disminuyó cuando PT y PE estuvieron más separadas. Hubo ligeras ventajas de utilizar DEBV como variables de respuesta en lugar de EBV.

PALABRAS CLAVE: Evaluación genómica, Valor genético predicho ajustado, Valor genómico predicho, Correlación genética.

Recibido el 30 de agosto de 2016. Aceptado el 2 de noviembre de 2016.

a Posgrado en Producción Animal, Departamento de Zootecnia, Universidad Autónoma Chapingo, Carretera México-Texcoco km 38.5. Chapingo, 56230 Estado de México. México.

${ }^{\mathrm{b}}$ Facultad de Zootecnia y Ecología, Universidad Autónoma de Chihuahua. Chihuahua, Chihuahua. México.

*Autor de correspondencia: arf@correo.chapingo.mx 
Genetic improvement depends on genetic variation, selection intensity, generation interval, and accuracy of estimated breeding values (EBV). In the genetic evaluation of animals, it is important to maximize EBV accuracy. An increase in EBV accuracy for selection of candidate animals will spur genetic progress. Among other advantages, the use of genomic selection allows an increase in the accuracy of genetic values ${ }^{(1)}$, especially at a young age ${ }^{(2)}$. Three technological breakthroughs have boosted wide-spread DNA information use in animal breeding $^{(3)}$ : the development of genomic selection technology, the discovery of massive numbers of genetic markers (SNPs), and high throughput costeffective genotyping technology. Although the advantages of genomic selection have been observed most notoriously in dairy cattle ${ }^{(4)}$, in general, the use of genomic selection can be expected to yield improvements in genetic progress of up to $10 \%$ in any species ${ }^{(4)}$.

In genomic evaluation, response variables can be individual phenotypes, repeated observations, records on close family members such as progeny, EBVs or their deregressed counterparts from genetic evaluations ${ }^{(5,6)}$. According to these authors, using deregressed EBV (DEBV), an accuracy of up to 2.76 times higher than with records of a single individual can be obtained. With average daily gain and feed conversion ratio of swine data, obtained accuracies were 18 to $39 \%$ higher, depending on the trait evaluated, when DEBVs were used as response variables instead of $\mathrm{EBVS}^{(7)}$. These authors concluded that DEBV is the preferred response variable, whereas the choice of statistical method was less critical when they analyzed purebred swine data. The increase of 18 to $39 \%$ in reliability is worthwhile, since the reliabilities of the genomic breeding values directly affect the returns from genomic selection $^{(7)}$.

Deregressed EBVs, with the parent average removed, produce more exact predicted genomic values (GV) for two reasons ${ }^{(5)}$. First, DEBVs, when used as the response variable, result in fewer double counts than when EBVs are used because the DEBVs exclude information from the individual's ancestors. If both the offspring and its parents are genotyped, the degree of double count decreases when DEBVs are used as the response variable. Second, when using EBVs as the response variable, the degree of double count in the GVs decreases, particularly when the reliabilities of the genetic values are low.

However, DEBVs are not always the best choice for use as the response variable in genomic evaluation. Simulated dairy cattle ${ }^{(6)}$ and jumping horse $^{(8)}$ data were used to compare EBVs and DEBVs as response variables. Both groups of authors found only slight advantages to using DEBVs, instead of conventional EBVs, as response variables. The objectives of this study were to compare the accuracy of genomic values and to estimate the genetic correlation between true genetic values and genomic values obtained using predicted breeding values (EBV) and deregressed EBV (DEBV) as response variables for four training populations and four evaluation generations.

The methodology for simulating the training (PEn) and evaluation (PEv) populations used in this study was described previously ${ }^{(9)}$. Briefly, two populations using the QMSim program ${ }^{(10)}$ were simulated. The first, to obtain linkage disequilibrium, had 800 individuals as the effective population size and 100 generations. The second population, where PEn and PEv originated, had 14 discrete generations, each of which was generated randomly using 20 males and 200 females, a panel of 53,010 SNPs (each evenly separated by 100 centiMorgans) randomly placed in 30 chromosomes, and 540 QTLS with effects coming from a gamma distribution ${ }^{(11)}$. Both SNPs and QTLs were regarded as biallelic with random starting frequencies. Genotypes and phenotypes of 6,400 individuals were simulated; the heritability used was 0.4 and only additive effects were considered. Genotypic and phenotypic information was generated using the QMSim program $^{(10)}$. The four PEn comprised generations 10 $(n=1,000) ; 9$ and $10(n=1,400) ; 8$ to $10(n=$ $1,800)$; and 7 to $10(n=2,200)$; as well as their phenotypes and the corresponding EBVs and DEBVs. The four PEv comprised generations 11 to 14 .

In a first step, the EBVs were predicted with a single-trait animal model including the random effect of animal, the fixed effects of sex of the individual, and generation. The ASREML program ${ }^{(12)}$ was used at this stage. The DEBVs were then obtained 
following methodology of Garrick et $a^{(5)}$. Weight $\left(w_{i}\right)$ for the $i^{\text {th }}$ animal was obtained using the following equation ${ }^{(5)}$ :

$$
\mathrm{w}_{\mathrm{i}}=\left(1-\mathrm{h}^{2}\right) /\left[\left(\mathrm{c}+\left(1-\mathrm{r}^{2}\right) / \mathrm{r}^{2}\right) \mathrm{h}^{2}\right]
$$

Where $\mathrm{c}$ is the lack of fit of the prediction equation, or the genetic part not explained by the markers ${ }^{(5)}$; the value assumed was $\mathrm{c}=0.1$; heritability of the trait, $h^{2}$, was assumed to be 0.4 ; and $r^{2}$ was the reliability of the DEVGs for the $i^{\text {th }}$ animal.

Deregression of EBVs adjusts for ancestral information, it removes shrinkage present in EBV, and by taking parental contribution into account, DEBVs can be regarded as equivalent to the information provided by the records of each sire and its progeny ${ }^{(13)}$.

In a second step, the predicted genetic values (EBVs) obtained using ASREML and their corresponding DEBVs were used as response variables to predict the GVs. A weighted genomic analysis was carried out using the BayesC $\pi$ function of the Gen-Sel program ${ }^{(14)}$. A 41,000-round long chain was used. The last 1,000 samples were used to obtain the a posteriori mean estimates of marker effects and variances. The first 40,000 iterations were regarded as the burn-in period; $\pi$ was fixed at 0.95. The genomic analysis used animals of generations 7 to 10 to obtain the prediction equations. The evaluation populations were generations 11 to 14 . The Bioinformatics to Implement Genomic Selection (BIGS) platform (http://bigs.ansci.iastate.edu/) platform was used for the analysis.

The genomic values and their corresponding accuracies were obtained by summing all the SNP effects, using the following equation:

$$
\mathrm{GVn}_{i}=\sum_{j=1} z_{i j} \hat{u}_{j}
$$

Where $G V n_{i}$ is the genomic value for the $i^{\text {th }}$ individual; $z_{i j}$ is the genotype of the $j^{\text {th }}$ marker on the $i^{\text {th }}$ individual, and $\hat{u}_{j}$ is the a posteriori mean of SNP effect for the $\mathrm{j}^{\text {th }}$ marker.

Accuracies $\left(R^{2}\right)$ of $G V s$ were obtained as the square of the correlation between GVs and the true genetic values ${ }^{(6,13,15)}$. Criteria for comparing the two alternatives of analysis were $\mathrm{R}^{2}$ and GV prediction error variance (PEV). Additionally, as another criterion for comparing the two response variables studied, the genetic correlation estimates was used between the true genetic values and the predicted GVs from the two alternatives of genomic analysis( ${ }^{(6)}$. These estimates were obtained using ASREML ${ }^{(12)}$.

An important aspect in genetic improvement is the response to selection, and this depends on selection accuracy ${ }^{(16)}$. Table 1 shows the means and

Table 1. Mean \pm standard deviation for accuracy $\left(R^{2}\right)$ and prediction error variance (PEV) of genomic values obtained using deregressed predicted genetic values as response variables, four training populations, and four generations of evaluation

\begin{tabular}{lcccc}
\hline & \multicolumn{4}{c}{ Training population } \\
\cline { 2 - 5 } Evaluation generation & 10 & 9 and 10 & 8 to 10 & 7 to 10 \\
\hline $\mathrm{R}^{2}$ & & & & \\
11 & $0.52 \pm 0.04$ & $0.67 \pm 0.03$ & $0.73 \pm 0.03$ & $0.77 \pm 0.01$ \\
12 & $0.39 \pm 0.04$ & $0.55 \pm 0.03$ & $0.63 \pm 0.03$ & $0.68 \pm 0.03$ \\
13 & $0.32 \pm 0.05$ & $0.49 \pm 0.04$ & $0.58 \pm 0.03$ & $0.64 \pm 0.03$ \\
14 & $0.28 \pm 0.06$ & $0.45 \pm 0.04$ & $0.54 \pm 0.04$ & $0.60 \pm 0.03$ \\
\hline $\mathrm{PEV}$ & & & & \\
11 & $0.05 \pm 0.003$ & $0.05 \pm 0.003$ & $0.04 \pm 0.003$ & $0.04 \pm 0.003$ \\
12 & $0.06 \pm 0.004$ & $0.06 \pm 0.004$ & $0.06 \pm 0.004$ & $0.05 \pm 0.004$ \\
13 & $0.07 \pm 0.005$ & $0.07 \pm 0.005$ & $0.06 \pm 0.005$ & $0.06 \pm 0.005$ \\
14 & $0.07 \pm 0.006$ & $0.08 \pm 0.006$ & $0.07 \pm 0.006$ & $0.07 \pm 0.005$ \\
\hline
\end{tabular}


corresponding standard deviation for $\mathrm{R}^{2}$ and PEV of GVs obtained from the different combinations of PEn and PEv when the response variable was DEBV. The highest $R^{2}, 0.77 \pm 0.01$, was observed for the largest training population (generations 7 to $10, n=2,200$ individuals) and 11 was the generation under evaluation. In contrast, the lowest mean for $\mathrm{R}^{2}, 0.28$ \pm 0.06 , was observed for the combination of the smallest training population and the farthest evaluation population being evaluated, generation 14. These results are within the range of $R^{2}$ values reported by Hassani et $a^{(17)}$, who found $0.49( \pm 1$ SNP) to 0.75 ( $\pm 100 \mathrm{SNPs})$ using whole-genome training for single QTL with a $50 \mathrm{~K}$ SNP panel and BayesCO.

Two clear trends can be observed for $\mathrm{R}^{2}$ in Table 1. First, as PEn and PEv moved farther apart, $\mathrm{R}^{2}$ decreased. Second, as the size of PEn decreased, $R^{2}$ became smaller. These results are similar to those reported by other research groups ${ }^{(18-21)}$, who concluded that the closer the relationship between individuals in PEn and those in PEv, the higher the $\mathrm{R}^{2}$ of GVs. Similarly, using both simulated and real sheep data, Genomic Best Linear Unbiased Prediction was compared with two pedigree based methods ${ }^{(22)}$. It was found that both empirical and estimated accuracy of GVs were different for several degrees of relationship. These authors concluded that $R^{2}$ of GVs is proportional to the genetic relationship of animals under selection to the reference population. The increase in $\mathrm{R}^{2}$ of $\mathrm{GVS}$ when PEn and PEv are closely related, can be explained by more precise genomic relationships, improving in this way the connectedness between these populations and more distant populations. Accordingly, another research group ${ }^{(23)}$ concluded that accuracy of GVs deteriorated as the relationship between animals in the PEn and those under selection decreased. One implication of this is that PEn has to be regularly updated to keep the marker effect estimates in sync with new generations of the breeding population ${ }^{(2)}$.

On the other hand, as expected, the trend for $\mathrm{R}^{2}$ held true for PEV, but in the opposite direction. The greater the population size and the closer relationship between PEn and PEv, the lower PEV. Pszczola et $a{ }^{(15)}$ mentioned that PEV can be calculated as the connectedness between the reference population and the animals under evaluation. This may explain the increase in PEV as PEn and PEv became farther apart. Greater connectedness reduces bias, and thus genetic evaluation improves ${ }^{(24)}$. The observed trend for PEV held true for both EBV and DEBV response variables.

Table 2 shows the means and their corresponding standard deviations for $\mathrm{R}^{2}$ and PEV for the combinations of PEn and PEv when the response variable was EBV. In general, $R^{2}$ values were only slightly lower than those observed when DEBVs were used as response variables. The trends

Table 2. Mean \pm standard deviation for accuracy $\left(R^{2}\right)$ and prediction error variance (PEV) of genomic values obtained using predicted genetic values as response variables, four training populations, and four generations of evaluation

\begin{tabular}{lcccc}
\hline & \multicolumn{4}{c}{ Training population } \\
\cline { 2 - 5 } Evaluation generation & 10 & 9 and 10 & 8 to 10 & 7 to 10 \\
\hline $\mathrm{R}^{2}$ & & & & \\
11 & $0.48 \pm 0.04$ & $0.65 \pm 0.03$ & $0.71 \pm 0.02$ & $0.76 \pm 0.02$ \\
12 & $0.38 \pm 0.05$ & $0.55 \pm 0.03$ & $0.62 \pm 0.03$ & $0.68 \pm 0.02$ \\
13 & $0.32 \pm 0.05$ & $0.49 \pm 0.03$ & $0.58 \pm 0.03$ & $0.64 \pm 0.03$ \\
14 & $0.28 \pm 0.06$ & $0.45 \pm 0.04$ & $0.54 \pm 0.04$ & $0.60 \pm 0.03$ \\
\hline $\mathrm{PEV}$ & & & & \\
11 & $0.05 \pm 0.003$ & $0.05 \pm 0.003$ & $0.04 \pm 0.003$ & $0.04 \pm 0.003$ \\
12 & $0.05 \pm 0.004$ & $0.06 \pm 0.004$ & $0.06 \pm 0.004$ & $0.05 \pm 0.004$ \\
13 & $0.06 \pm 0.004$ & $0.07 \pm 0.005$ & $0.06 \pm 0.004$ & $0.06 \pm 0.004$ \\
14 & $0.06 \pm 0.005$ & $0.07 \pm 0.006$ & $0.07 \pm 0.005$ & $0.06 \pm 0.005$ \\
\hline
\end{tabular}


observed for the decrease in $\mathrm{R}^{2}$ and the increase in PEV when DEBVs were response variables, as size of PEn diminished and the distance between PEn and PEn augmented, held true for EBVs used as response variables. These results are similar to those obtained by other authors ${ }^{(25,26,27)}$, who found that size of PEn affected $R^{2}$ of GVs. The results of the present study and those obtained by other groups of researchers agree with what could be theoretically expected ${ }^{(1,28)}$. These authors developed predictive equations for accuracy of predicted genomic values, which depend on size of PEn, effective population size of the breed, heritability of the trait, and length of genome.

The results of a study with two multi-breed beef cattle populations and Angus and Hereford purebred populations $^{(13)}$ used to obtain the GVs and corresponding $\mathrm{R}^{2}$ for six growth and carcass traits showed that accuracies were lower for prediction equations trained in a single breed. These results were attributed to the smaller number of records derived from a single breed in the training populations. The $R^{2}$ range was $0.01 \pm 0.10$ to 0.65 \pm 0.07 , although the authors also reported a negative estimate, $-0.10 \pm 0.15$.

The results of this work, regardless of whether DEBV or EBV were used as response variables, are

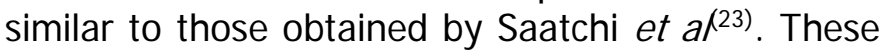
authors evaluated different training populations of Hereford cattle; accuracy estimates ranged from 0.15 to 0.52 , with 0.30 on average when trained on old animals and validated on young animal populations. The results obtained in our study may be explained by the fact that genomic prediction on closely related individuals is based on relationship; genomic relationships are more accurate when the relationships between PEn and PEv populations are close $^{(3)}$. On the other hand, prediction on distant individuals requires DL between QTL and markers ${ }^{(29)}$.

The $\mathrm{R}^{2}$ results are lower than those reported by Pszczola et $a r^{(30)}$. These authors found that the inclusion of animals with predicted genotypes in the reference population did not significantly increase accuracies of GVs for juvenile animals. They attributed the lack of significance to the low accuracy of predicted genotypes and concluded that inclusion of non-genotyped animals is expected to enhance genomic selection accuracy only when the unknown genotypes can be predicted with high accuracy. The results obtained by these authors varied from 0.57 to 0.96 , from 0.48 to 0.88 , and from 0.33 to 0.72 for heritabilities of $0.30,0.05$, and 0.01 , respectively, under different sizes of the reference population, and different numbers of animals with known or predicted genotypes.

The small difference in GV accuracy that we obtained in our study when EBVs or DEBVs were the response variables agree with reports by other researchers. However, these results are opposite to those observed by Ostersen et $a^{(7)}$, who found 18 to $39 \%$ higher accuracies for feed conversion ratio and daily gain when they used DEBVs instead of EBVs as response variables. The estimation methodologies they used were GBLUP, Bayesian Lasso, and MIXTURE, where the marker effects are assumed to follow a normal distribution, double exponential, and a mixture of two normal distributions, respectively. The three alternatives of analysis yielded similar reliabilities of the GVs for the two traits analyzed.

Contrary to our results, Ricard et $a^{(8)}$ did not find substantial advantages to genomic values obtained using deregressed EBVs as response variables or the GBLUP and BayesC $\pi$ alternatives of analysis compared with conventional BLUP predictions. They followed a specific deregression procedure that included not only the individual's own performance, but also the performance of several relatives (not just offspring), in addition to the genotyped sample. This regression procedure was easy to implement from EBVs, reliabilities, and pedigrees. Unfortunately, accuracy of genomic evaluation, measured by cross validation in several validation samples, was not enough to suggest its use in current breeding plans for the jumping horse population studied. However, the authors mention that this conclusion is related only to accuracy, and the potential benefits of a higher selection intensity, reduced generation intervals, and low inbreeding in the long run should be considered when genomic selection in horses is planned. In dairy cattle similar results were reported ${ }^{(6)}$. The authors compared two response variables, EBVs and daughter yield deviations (DYD) on simulated dairy data under eight scenarios of heritability, number of daughters 
per sire, and number of genotyped sires. They found that DYDs yielded slightly lower reliabilities than EBVs. The average differences in GV accuracy of between EBVs and DYDs were 0.009 for $h^{2}=0.30$, and 0.035 when $h^{2}=0.05$.

Table 3 presents the genetic correlation estimates between true genetic values and the GVs $r_{(T B V, G V)}$ obtained using DEBVs and EBVs as response variables. A slight advantage of using DEBVs, range 0.43 to 0.53 , instead of EBVs, range 0.41 to 0.51 , held constant throughout all training population sizes. Also, genetic correlation estimates decreased as PEn and PEv separated. The $r_{(\mathrm{TBV}, \mathrm{GV})}$ estimates of the present study are higher than those observed by Alarcón-Zúñiga et $a^{\left({ }^{9}\right)}$, range 0.29 to 0.40 , using the same dataset but different models for the genomic analysis. Genetic correlation estimates between direct genomic values and phenotypes from k-fold validation in Red Angus, Angus, Hereford, Simmental and Limousin ranged from 0.32 to 0.85 for birth weight, weaning weight, milk yield, rib eye muscle area, marbling, direct calving ease, and maternal calving ease ${ }^{(21,31)}$. Similarly, genetic correlation estimates between true genetic values and GVs for marbling, using data sets with different proportions of available information, ranged from 0.256 to $0.859^{(32)}$. Guo et $a^{(6)}$ found genetic correlation estimates between GVs and conventional parent average ranging from 0.457 to 0.688 using three statistical models and eight combinations of heritability and number of daughters per sire.

Some limitations of our work are that a distance between training and evaluation populations needs to be more specific, and size and number of

Table 3. Genetic correlation estimates between true genetic values and genomic values obtained using deregressed predicted genetic values (DEBV) or predicted genetic values (EBV) as response variables, with four training populations

\begin{tabular}{lll}
\hline & \multicolumn{2}{l}{ Response variable } \\
\cline { 2 - 3 } Training population & DEBV & EBV \\
\hline 10 & 0.53 & 0.51 \\
9 y 10 & 0.51 & 0.50 \\
8 a 10 & 0.48 & 0.47 \\
7 a 10 & 0.43 & 0.41 \\
\hline
\end{tabular}

generations in the training population also need to be better determined. Moreover, since our study used simulated information, it does not entirely correspond to real production system conditions.

The advantage of using deregressed predicted genetic values as the response variable, instead of conventional predicted genetic values, was very slight with any combination of training population size and evaluation generation. Regardless of the response variable used, predicted genetic value or deregressed predicted genetic value, larger training population were associated with higher genomic values accuracy.

Prediction error variance was low and similar with any combination of training population size and evaluation generation, regardless of the response variable used. The genetic correlation estimates between true genetic values and genomic values obtained using DEBV as the response variable were slightly higher than those between true genetic values and genomic values obtained using EBV as the response variable.

\section{ACKNOWLEDGEMENTS}

The authors thank CONACYT for the financial support for the Master of Science studies in Animal Production of the first author.

\section{CITED LITERATURE}

1. Goddard ME. Genomic selection: Prediction of accuracy and maximization of long term response. Genetica 2009; 136:245-257.

2. Knol EF, Nielsen B, Knap PW. Genomic selection in commercial pig breeding. Anim Front 2016; 6: 15-22.

3. Meuwissen TB. Hayes B, Goddard M. Genomic selection: A paradigm shift in animal breeding. Anim Front 2016;6:6-14.

4. I banez-Escriche N, Simianer H. Animal breeding in the genomic era. Anim Front 2015;5:4-5.

5. Garrick DJ, Taylor JF, Fernando R. Deregressing estimated breeding values and weighting information for genomic regression analyses. Genet Sel Evol 2009;41:55-62.

6. Guo G, Lund MS, Zhang Y, Su G: Comparison between genomic predictions using daughter yield deviation and conventional estimated breeding value as response variables. J Anim Breed Genet 2010; 127:423-432. 
7. Ostersen T, Christensen OF, Henryon M, Nielsen B, Su G, Madsen $P$. Deregressed EBV as the response variable yield more reliable genomic predictions than traditional EBV in pure-bred pigs. Genet Sel Evol 201;43:38-43.

8. Ricard A, Danvy S, Legarra A. Computation of deregressed proofs for genomic selection when own phenotypes exist with an application in French show-jumping horses. J Anim Sci 2013;91:1076-1085.

9. Alarcón-Zúñiga B, Ramírez-Flores F, Ruíz-Flores A, RamírezValverde R, Saavedra-J iménez LA, Zepeda-Batista J L. Comparación de la exactitud de valores genómicos de animales predichos a través del análisis con dos modelos alternativos. Agrociencia 2015; 49:613-622.

10. Sargolzaei M, Schenkel FS. QMSim: a large-scale genome simulator for livestock. Bioinformatics 2009;25:680-681.

11. Weller JI, Shlezinger M, Ron M. Correcting for bias in estimation of quantitative trait loci effects. Genet Sel Evol 2005;37:501-522.

12. Gilmour AR, Gogel, BJ , Cullis, BR, Thompson R. ASREML User Guide Release 3.0 VSN International Ltd, Hemel Hempstead, HP1 1ES, UK. http://www.vsni. co.uk. 2009. Consulted J an 31, 2014.

13. Weber KL, Thallman RM, Keele JK, Snelling WM, Bennet GL, Smith TPL, et al. Accuracy of genomic breeding values in multibreed beef cattle populations derived from deregressed breeding values and phenotypes. J Anim Sci 2012;94:4177-4190.

14. Fernando R, Garrick DJ. GenSel - user manual for a portfolio of genomic selection related analyses, create 9.1. http://bigs. ansci.iastate.edu/bigsgui/ReleaseNotes/Version9_1Rele aseNotes.1.pdf. 2009. Accessed Jan 15, 2013.

15. Pszczola M, Strabel T, Mulder HA, Calus MPL. Reliability of direct genomic values for animals with different relationships within and to the reference population. J Dairy Sci 2012;95:389-400.

16. Pszczola M, Strabel T, van Arendonk JAM, Calus MPL. The impact of genotyping different groups of animal son accuracy when moving from traditional to genomic selection J Dairy Sci 2012;95:54125421.

17. Hassani S, Saatchi M, Fernando RL, Garrick DJ. Accuracy of prediction of simulated polygenic phenotypes and their underlying quantitative trait loci genotypes using real or imputed wholegenome markers in cattle. Genet Sel Evol 2015;47:99-109.

18. Habier D, Fernando RL, Dekkers JCM. The impact of genetic relationship information on genome-assisted breeding values. Genetics 2007; 177:2389-2397.

19. Habier D, Tetens J, Seefried F-R, Lichtner P, Thaller G. The impact of genetic relationship information on genomic breeding values in German Holstein cattle. Genet Sel Evol 2010;52:5-16.

20. Saatchi M, Miraei-Ashtiani SR, Nejati Javaremi A, MoradiShahrebabak M, Mehrabani-Yeghaneh $\mathrm{H}$. The impact of information quantity and strength of relationship between training set and validation set on accuracy of genomic estimated breeding values. Afr J Biotech 2010;9:438-442.

21. Saatchi M, McClure MC, McKay SD, Rolf MM, Kim J, Decker JE, et al. Accuracies of genomic breeding values in American Angus beef cattle using K-means clustering for cross-validation. Genet Sel Evol 2011;43:40-55.

22. Clark SA, Hickey JM, Daetwyler HD, van der Werf JHJ. The importance of information on relatives for the prediction of genomic breeding values and the implications for the makeup of reference data sets in livestock breeding schemes. Genet Sel Evol 2012;44:412.

23. Saatchi M, Ward J, Garrick DJ. Accuracies of direct genomic breeding values in Hereford beef cattle using national or international training populations. J Anim Sci 2013;91:1538-1551.

24. Kennedy BW. Bias and mean square error from ignoring genetic groups in mixed model sire evaluation. J Dairy Sci 1981;64:689697.

25. Meuwissen THE, Hayes BJ, Goddard ME. Prediction of total genetic value using genome-wide dense marker maps. Genetics 2001; 157:1819-1829.

26. Calus, MPL, Veerkamp RF. Accuracy of breeding values when using and ignoring the polygenic effect in genomic breeding value estimation with a marker density of one SNP per CM. J Anim Breed Genet 2007; 124:362-368.

27. Muir WM. Comparison of genomic and traditional BLUP-estimated breeding value accuracy and selection response under alternative trait and genomic parameters. J Anim Breed Genet 2007; 124:342355.

28. Daetwyler HD, Pong-Wong R, Villanueva B, Woolliams JA. The impact of genetic architecture on genome-wide evaluation methods. Genetics 2010; 185: 1021-1031.

29. Daetwyler HD, Kemper KE, van der Werf JHJ. Hayes BJ. Components of the accuracy of genomic prediction in a multi-breed sheep population. J Anim Sci 2012; 90:3375-3384.

30. Pszczola M, Mulder HA, Calus MPL. Effect of enlarging the reference population with (un)genotyped animals on the accuracy of genomic selection in dairy cattle. J Dairy Sci 2011;94:431-441.

31. Saatchi M, Schnabel RD, Rolf MM, Taylor JF, Garrick DJ. Accuracy of direct genomic breeding values for nationally evaluated traits in US Limousin and Simmental beef cattle. Genet Sel Evol 2012;44:38.

32. Spangler ML, Bertrand JK, Rekaya R. Combining genetic test information and correlated phenotypic records for breeding value estimation. J Anim Sci 2007;85:641-649. 